Engineer Research and

Development Center

Engineer Site Identification for the Tactical Environment (ENSITE)

\title{
Military Climate Resilience Planning and Contemporary Urban Systems Thinking
}

James P. Allen and Brian M. Deal

December 2017 
The U.S. Army Engineer Research and Development Center (ERDC) solves the nation's toughest engineering and environmental challenges. ERDC develops innovative solutions in civil and military engineering, geospatial sciences, water resources, and environmental sciences for the Army, the Department of Defense, civilian agencies, and our nation's public good. Find out more at www.erdc.usace.army.mil.

To search for other technical reports published by ERDC, visit the ERDC online library at http://acwc.sdp.sirsi.net/client/default. 


\section{Military Climate Resilience Planning and Contemporary Urban Systems Thinking}

James P. Allen

Construction Engineering Research Laboratory

U.S. Army Engineer Research and Development Center

2902 Newmark Drive

Champaign, IL 61822

Brian M. Deal

University of Illinois

Department of Urban and Regional Planning

228 Temple Buell Hall

611 Lorado Taft Drive

Champaign, IL 61820

Final report

Approved for public release; distribution is unlimited.

Prepared for Assistant Secretary of the Army for

Acquisition, Logistics, and Technology (ASA(ALT))

103 Army Pentagon

Washington, DC 20314-1000

Under Project 455009, “Contingency Base Site Identification for the Tactical Environment" 


\section{Abstract}

Climate change adaptation is now recognized through many formal government policies as a desired strategic end state, with resilience as the identified means to achieve it. Military and security agencies clearly see that climate change adds significantly to instability, hunger, poverty, and conflict. Thus the military requires planning consideration for risk environments. The evolving military concept of resilience can leverage sustainability and smart concepts with added emphasis on security and planned risk response strategies.

The work reported here establishes the nexus of climate change adaptation with military resilience planning, reviews the military's use and definition of resilience as a concept, and explores what the military might learn from urban planning and nonmilitary versions of resilience. It also examines planners' focus on engineering resilience at the project level and at the system level. A gap in planning for resilience at the community (or regional) levels is recognized in the current military planning paradigm, and this work examines how planners can fill this gap and benefit by expanding the current resilience framework. This broadened and more comprehensive consideration of resilience will enhance climate change adaptation strategies of the military, and resilience should be incorporated into overall military planning.

DISCLAIMER: The contents of this report are not to be used for advertising, publication, or promotional purposes. Citation of trade names does not constitute an official endorsement or approval of the use of such commercial products. All product names and trademarks cited are the property of their respective owners. The findings of this report are not to be construed as an official Department of the Army position unless so designated by other authorized documents. 


\section{Contents}

Tabstract...

1 Introduction: Climate Change Adaptation and Military Resilience

Planning............................................................................................................ 1

2 History of the Term "Resilience": Multiple Meanings in Various Fields.................... 3

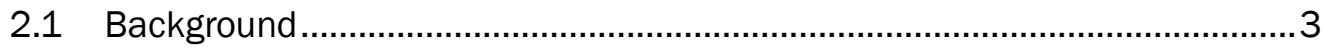

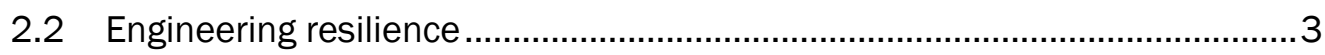

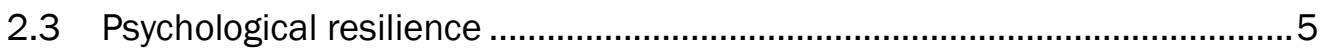

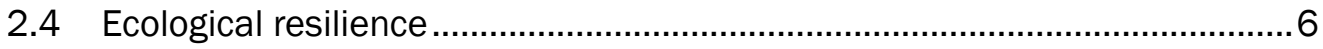

3 Resilience in Military Context: How to Mitigate Threats with Action Plans............. 9

3.1 Personal resilience ............................................................................... 9

3.2 Systems approach to resilience...........................................................11

3.2.1 Planning factors ....................................................................................... 12

3.2.2 Fault-tolerant infrastructure .................................................................... 13

3.2.3 Adaptive solutions.................................................................................. 13

3.2.4 Critical asset redundancy ........................................................................ 13

3.2.5 Mitigation............................................................................................... 14

3.2.6 Risk response strategies ....................................................................... 14

4 Resilience in Urban Planning: Using Urban Socio-Ecology Concepts to Enhance Military Resilience Planning for Climate Change Adaptation .................16

5 Summary and Conclusions: Improved Military Climate Resilience Planning with Contemporary Urban Systems Thinking ......................................24

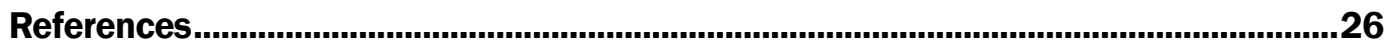

\section{Report Documentation Page}




\section{Tables}

Table 1. Varied resilience definitions and contexts, with potential climate adaptation considerations (adapted from Hassler and Kohler 2014). ................................. 7 


\section{Preface}

This study was conducted for the Assistant Secretary of the Army for Acquisition, Logistics, and Technology (ASA(ALT)) under T45, Project 455009, "Contingency Base Site Identification for the Tactical Environment.”

The work was performed by the Engineering Processes Branch (CFN) of the Facilities Division (CF), U.S. Army Engineer Research and Development Center, Construction Engineering Research Laboratory (ERDCCERL). At the time of publication, Mr. Charles G. Schroeder was Chief, CEERD-CFN; Mr. Donald K. Hicks was Chief, CEERD-CF; and Mr. Kurt Kinnevan, CEERD-CZT was the Technical Director for Adaptive and Resilient Installations. The Interim Deputy Director of ERDC-CERL was Ms. Michelle Hanson, and the Interim Director was Dr. Kumar Topudurti.

The Commander of ERDC was COL Bryan S. Green, and the Director was Dr. David W. Pittman. 


\title{
Foreword
}

This work was originally presented as part of the Framing Climate Security panel on 4 April 2017, during the "Conscripting Climate: Environmental Risk and Defensive Urbanism" symposium held that day by the Department of Urban Studies and Planning at the Massachusetts Institute of Technology in Cambridge, Massachusetts.

The work was also published as part of the Projections journal of the MIT Department of Urbana Studies and Planning as Projections 13: Conscripting Climate: Environmental Risk and Defensive Urbanism (Fall 2017).

This report captures that information, with slight editing and formatting to meet ERDC publishing standards.

\author{
JEAN S. NOELLSCH \\ Writer-Editor (CTR) \\ Information Science and Knowledge Management \\ Information Technology Laboratory (ERDC-ITL)
}




\section{Introduction: Climate Change Adaptation and Military Resilience Planning}

As populations swell and the realities of climate change bear down on urban centers, understanding the future consequences of current military planning and design decisions becomes increasingly important. Globally, urbanized populations are expected to reach 66\% by 2050 (UN 2014), while changing regional climatic profiles are expected to produce extreme events (heat, cold, rain, and drought) (IPCC 2014). These phenomena are expected to have a concentrated effect in heavily populated urban areas where low albedo surfaces exacerbate urban heat island effects, density magnifies anthropogenic pollution and water problems, and more frequent and extreme weather events severely impact less stable socio-economic groups (IPCC 2014; Dorer et al. 2013; Carter et al. 2015; Stewart and Oke 2012). These facts have caused governments to respond with policies and regulations to address anticipated climate change impacts.

Climate change is now codified in international and national government policy, with direct relevance to military and security agency planners. This paper considers the term "military" to include the uniformed defense services (i.e., Army, Navy, Air Force, Marines, and their associated joint agencies or operations). The term "security agency" is used to include typically non-uniformed agencies of both national and homeland security, including the multitude of federal agencies that gather intelligence and lead planning efforts to ensure the protection and effectiveness of people, systems, and information, including those identified as "sector-specific agencies" in Presidential Policy Directive-21, "Critical Infrastructure Security and Resilience." An official definition of climate change is now incorporated into the U.S. Department of Defense (DoD) Dictionary of Military and Associated Terms as "variations in average weather conditions that persist over multiple decades or longer that encompass increases and decreases in temperature, shifts in precipitation, and changing risk of certain types of severe weather events" (DoD 2018, 38). Adaptation to deal with this effect is also defined in Department of Defense Directive (DoDD) 4715.21, titled "Climate Change Adaptation and Resilience" as "adjustment in natural or human systems in anticipation of or response to a changing environment in a way that effectively uses beneficial opportunities or reduces negative efforts" (DoD 2016). Thus, the desire to minimize risk 
through climate change adaptation in order to protect the health, safety, and welfare of a population is formally part of many government planning processes. The DoD has published the 2014 Climate Change Adaptation Road Map (DoD 2014), which lays out a vision and supporting goals to meet this end-state objective in the interest of national security.

Military and security agencies may not consider climate change as a direct or immediate threat, but they can clearly see how it contributes to regional instability, hunger, poverty, and conflict and, that it requires planning consideration for present and future risk environments. The result is a blending of planning considerations by both military and security agency planners with the considerations of more traditional urban planners related to climate change, security, sustainability, smart concepts, and resilience. The military and security agencies are working to understand all the facets related to resilient systems. The evolving military concept of resilience can leverage various sustainability and smart concepts of the past two decades with an added emphasis on security and planned risk response strategies. This blending of interdisciplinary expertise provides extensive opportunities for collaboration and shared learning between military and urban planners.

The contemporary nexus of climate change adaptation with military resilience planning calls for a brief review of the historic and interdisciplinary use of resilience as a concept, as well as an understanding of the current and particular definition of resilience utilized by the military within these myriad fields, to allow an exploration of what the military might learn from urban planning and non-military versions of resilience. This paper examines the military and security agency planners' current policies and understandings of resilience; it focuses first on engineering resilience at the project level and then at the system level, and it identifies a gap in planning for resilience at the community (or regional) levels in the current military planning paradigm. This paper then explores how the military and security agency planners can fill this gap and benefit by expanding the current resilience framework to emphasize contemporary urban and regional planning concepts and tools that involve sustainability, smart concepts, urban ecology, and enhanced socio-environmental aspects of resilience to more fully consider climate change. This paper concludes that transdisciplinary planning efforts will help better frame the dynamic concept of resilience and integrate the many facets of urban ecological resilience into climate change adaptation strategies. 


\section{History of the Term "Resilience": Multiple Meanings in Various Fields}

\subsection{Background}

A more fully informed understanding of resilience and its use in a multitude of disciplinary fields benefits from a recognition of the term's origins and evolution. This section will briefly review the term's origins in the engineering-related fields to demonstrate that even intradisciplinary use of the term resilience must begin by asking core-level questions. A further overview of resilience in the areas of psychology, organizations, and ecology will acquaint the reader with the different connotations and form the basis for exploring resilience in the military context of the following section. Table 1 at the end of this section shows the following: (a) a summary of all contextual meanings of resilience in various fields, (b) a lens for the military to identify potential gaps in resilience planning at the community and regional levels, and (c) proposed climate adaptation planning considerations for the military. Later chapters expand on the current urban planning approaches to resilience and more fully develop the evolving concept of urban ecology and urban resilience, along with providing tools that may benefit the military planning approach.

\subsection{Engineering resilience}

The term resilience in its earliest forms dates back more than three centuries, with its origins in the mechanical design realm related to ability of a material, component, or system to spring back from an externally applied force. ${ }^{*}$ Contemporary mechanics of materials courses in engineering colleges still consider resilience regarding the ability of a material to absorb and release energy within the elastic range, thus retaining its material properties. Resilience in engineering was expanded to infrastructure design and system designs as well. This design principle is utilized in those design guides and building codes today that require redundancy in critical elements and oversized components that allow for multiple-load actors and factors of safety (Hassler and Kohler 2014). The structural engineer balances the goal of optimizing strength while reducing the quantity of

\footnotetext{
* As defined at Dictionary.com (Random House Dictionary unabridged). Accessed 11 July 2017. Dictionary.com http://www.dictionary.com/browse/resilience.
} 
material requirements. This application of resilience in structural engineering lends to determining specific solutions for a particular set of anticipated, although possibly unlikely, pressures or loading scenarios that allow the component or system to retain its original design capacity within a multiple and varied loading condition scenario. Resilience in this original sense focused upon an approach to maintain stability and predictability and is applied in similar fashion across engineering fields.

Application of resilience to systems, however, resulted in a nuanced concept of resilience that recognized the complexities of most systems and that physical nature could change, while consistent functionality would provide retained capacity and thus, a resilient system. The use of resilience as a concept evolved from maintaining stability focused upon a single equilibrium of physical properties, to consider a single equilibrium of functional properties. A classic example shows that contrasting and contradictory results depend on how resilience is defined in engineering, and that definition will affect the design approach taken for a hospital building. A physically resilient hospital building may be designed with foundation, walls, roof, electrical, and air-conditioning systems that can withstand certain disaster scenarios while still providing high-quality hospital services. However, this overall building design has limited functionality such that it can only be utilized effectively as a hospital. What happens when the building's use must change, due to shifting market or social demands, to that of an office building, warehouse, or retail space? By instead using a functionally resilient design approach, the design may result in open floor plans and modular electrical and air-conditioning systems that are easily modified to suit different tenant needs other than a hospital; this type of design trades some of the specified physical resilience design aspects for functional resilience. Thus, even in the somewhat streamlined field of building design and construction, there is a need to ensure a common understanding of resilience and challenges in using the term.

The above example of different aspects of resilience brings to light three key questions which are important to answer, as follows: (1) Resilience to what? (2) Resilience of what? (3) Resilience for whom? (Hassler and Kohler 2014). In the hospital building example discussed above, it is seen the different answers to those key questions can skew the resilient design approach that targets a resilience to natural disaster events on one hand (intended to ensure continuity of medical operations for patients), to a resilient design approach that targets a resilience to changing market and 
economic conditions (intended to ensure functionality for present and future tenants and profitability for building owners). Does this difference in types of resilience indicate a futility in using resilience as a concept? While this example displays the challenges of using the term, the fact that answering these basic questions about resilience will the clarify the term's meaning to provide real design choices and impacts for engineering solutions simply argues for an informed use of resilience during planning and design.

\subsection{Psychological resilience}

While resilience is solidly rooted and established in the engineering discipline to which it owes a fair portion of its modern usage and application, the disciplines of psychology and ecology equally utilize the term today. The field of psychology began studying and using resilience in the mid-tolate 2oth century, with initial research on how severely disadvantaged children resisted negative outcomes and emerged unscathed from their circumstances (Graber et al. 2015). This research represented a paradigm shift from looking at the risk factors that led to psychological problems, to now identifying the characteristics of individuals who thrived while living in difficult circumstances, thus demonstrating resilience. The effort to understand and facilitate the promotion of resilience in the face of substantial adversity became the goal within psychology, and use of the term generally accepted a definition of human resilience as "the process of, capacity for, or outcome of successful adaptation despite challenging or threatening circumstances" (Masten 1990).

Psychologists' understanding of human functioning in demanding situations has grown significantly over the past two decades. The examination of resilience has ranged in contexts across business, education, military, sports, and communities (Fletcher and Sakar 2013). While adversity must first be present in order to form resilience, the key to psychological resilience is the concept of "positive adaptation," which is behaviorally manifested social competence or internal well-being (Fletcher and Sakar 2013). Case studies of events such as post-Hurricane Katrina or military posttraumatic stress continue to inform and develop the concept of psychological resilience. Resilience has grown from its original application to individuals to a broader social application to families and groups. Business case studies look at individual, team, and holistic organizational resilience in terms of flexibility, market response, and profitability with overt efforts to 
build organizational resilience. As will be examined in a following section, the military uses resilience as a measure of combat readiness.

However, even with the above generally agreed-upon definition of resilience in the field of psychology, the usefulness of the term is challenged due to the debate over whether it is truly a process, an individual capacity, or rather an eventual outcome. Therefore, the use of the term resilience can be as contested within psychology as it was in engineering because its measurement, prediction, and development is elusive. This elusive and even dynamic nature of resilience is something that has significantly been informed and shaped by the concept within ecology where ecosystem function is often characterized by constant change.

\subsection{Ecological resilience}

The ecological sciences have significantly shaped resilience theory and application. With a widely accepted definition of ecology as the study of the interactions of organisms with one another and their environment, ecology can trace its history to the 19th century but more recently, it has gained prominence during the environmental crisis of the mid-to-late 2oth century. Ecology begins with the study of individual physiologic, structural, and behavioral traits, but it then looks at characteristics of groups of organisms and then, at interactions of those groups. The science of ecology broadly includes landscapes and ecosystems, finding that the properties of the system emerge from the interaction of the system's parts (Pickett et al. 2013). Ecology by nature is largely transdisciplinary, relying on expertise in a multitude of fields to research a system and understand its underlying and emerging actions and reactions. Within this context, resilience in ecology can refer to the rapidity with which a system returns to its equilibrium after a disturbance, as measured in time units. While similar to other definitions, the equilibrium of ecosystems is characterized by a multitude of properties; thus ecological resilience helped introduce complexity and broader systems thinking into resilience concepts.

A significant premise of ecological research in the past few decades is that nature is not in constant balance, but rather it is in eternal flux that leads to a fundamental transformation in thinking from emphasizing equilibrium, homogeneity, and determinism to non-equilibrium, heterogeneity, and stochasticity, with an introduction of the concept of patch dynamics (Wu and $\mathrm{Wu}$ 2013). Observing that ecosystems often have multiple stable states, resilience in ecology is defined as the ability of a system to absorb 
change and disturbance without changing its basic structure and function or shifting into a qualitatively different state (Holling 1973). This resilience is based on multiple alternate states and is often labeled "ecological or ecosystem resilience," which stresses persistence, change, and unpredictability. Thus, ecological resilience contrasts with "engineering resilience," which stresses efficiency, constancy, and predictability (Wu and Wu 2013).

While ecology has faced criticism that it includes the study of the environment to the exclusion of humans, the 21st century has seen a new emergence of the inclusion of social and human nature into ecological discussions. Urban areas as ecosystems that include humans and their institutional arrangements and artifacts as components to the ecosystem has created the hybrid term "urban ecology" (Pickett et al. 2013). The Resilience Alliance is evidence of this deliberate effort because it is an international interdisciplinary partnership organized in 1999 that includes a diverse community of scientists and practitioners in academia, government, and other organizations. The partners have joined together to promote research on resilience in social-ecological systems (Wu and Wu 2013). These research opportunities offer an opportunity to holistically consider how the climate change phenomenon developed by studying the combination of humans with nature and an opportunity to offer insight into how people and institutions like the military can work within the system to intervene.

Table 1. Varied resilience definitions and contexts, with potential climate adaptation considerations (adapted from Hassler and Kohler 2014).

\begin{tabular}{|l|l|l|l|}
\hline Context & Definition/application & Reference & $\begin{array}{l}\text { Climate Considerations } \\
\text { for Military }\end{array}$ \\
\hline $\begin{array}{l}\text { Engineering Systems: } \\
\begin{array}{l}\text { Resilient and } \\
\text { sustainable } \\
\text { infrastructure design }\end{array}\end{array}$ & $\begin{array}{l}\text { Balancing short-term cost } \\
\text { with infrastructure need } \\
\text { to withstand natural and } \\
\text { human-made disasters }\end{array}$ & $\begin{array}{l}\text { Civil Engineering at } \\
(2017)^{*}\end{array}$ & $\begin{array}{l}\text { Built environment. } \\
\text { Design flood events, } \\
\text { temperature ranges, and } \\
\text { multi-hazard disaster } \\
\text { occurrence rates }\end{array}$ \\
\hline
\end{tabular}

* From the college's website: https://cee.illinois.edu/areas/sustainable-and-resilient-infrastructure-systems-program. Accessed March 2017. 


\begin{tabular}{|c|c|c|c|}
\hline Context & Definition/application & Reference & $\begin{array}{l}\text { Climate Considerations } \\
\text { for Military }\end{array}$ \\
\hline Ecological systems & $\begin{array}{l}\text { Measure of the } \\
\text { persistence of systems } \\
\text { and of their ability to } \\
\text { absorb change and } \\
\text { disturbance and still } \\
\text { maintain the same } \\
\text { relationships between } \\
\text { state variables. }\end{array}$ & Holling (1973) & $\begin{array}{l}\text { Land, sea, air, and space } \\
\text { domains. Natural } \\
\text { resource preservation } \\
\text { and socio- environmental } \\
\text { blending }\end{array}$ \\
\hline $\begin{array}{l}\text { Psychology: Individual } \\
\text { physical and mental } \\
\text { health }\end{array}$ & $\begin{array}{l}\text { Process of, capacity for, or } \\
\text { outcome of successful } \\
\text { adaptation despite } \\
\text { challenging or threatening } \\
\text { circumstances }\end{array}$ & $\begin{array}{l}\text { Gattis (2017) and } \\
\text { Masten (1990) }\end{array}$ & $\begin{array}{l}\text { Human domain. Coping } \\
\text { strategies in social and } \\
\text { organizational } \\
\text { interaction and } \\
\text { leadership }\end{array}$ \\
\hline Social systems & $\begin{array}{l}\text { Ability of communities to } \\
\text { withstand external shocks } \\
\text { to their social } \\
\text { infrastructure }\end{array}$ & Adger (2000) & $\begin{array}{l}\text { Land and human } \\
\text { domain. Peacekeeping } \\
\text { and stability operations. }\end{array}$ \\
\hline $\begin{array}{l}\text { Organizations, groups, } \\
\text { and business }\end{array}$ & $\begin{array}{l}\text { Ability of an organization } \\
\text { to anticipate, prepare for, } \\
\text { and respond and adapt to } \\
\text { incremental change and } \\
\text { sudden disruptions in } \\
\text { order to survive and } \\
\text { prosper }\end{array}$ & Everly (2011) & $\begin{array}{l}\text { Human domain. Social, } \\
\text { organizational, and } \\
\text { leadership. }\end{array}$ \\
\hline $\begin{array}{l}\text { U.S. military and } \\
\text { security agency policy }\end{array}$ & $\begin{array}{l}\text { Ability to anticipate, } \\
\text { prepare for, and adapt to } \\
\text { changing conditions and } \\
\text { withstand, respond to, } \\
\text { and recover rapidly from } \\
\text { disruptions }\end{array}$ & U.S. DoD (2016) & $\begin{array}{l}\text { Resilience as means to } \\
\text { achieve climate } \\
\text { adaptation }\end{array}$ \\
\hline
\end{tabular}




\section{Resilience in Military Context: How to Mitigate Threats with Action Plans}

Similar to the overall evolution of the term resilience and its use in multiple disciplines (as outlined in the previous chapter), resilience as a military term is contemporarily used at many levels and with many interrelated meanings. The medical and personnel fields of the military are closely tied to the psychological meaning of resilience. Soldier readiness and military leadership development fields tend toward the organizational components of resilience.

Engineers and disaster-response planners in the military are disposed to think of resilience related to infrastructure and the built environment. Chapter 3 examines the military context of resilience as it currently stands, explores the rational approach taken to develop climate adaptation mitigation strategies and action plans, and identifies the need for expanded understanding of resilience for communities at the urban and regional levels.

\subsection{Personal resilience}

Resilience is now applied at the personal soldier level by the Army to represent individual readiness. It is a command responsibility to optimize human performance in environments of uncertainty and persistent danger. The focus upon personal resilience grew from the increased suicide rate and occurrence of post-traumatic stress of soldiers during an increase in operational tempo after the 9/11 terrorist attacks upon the United States. A "ready and resilient" force is a stated strategic objective, with the Army Comprehensive Soldier Fitness Program aimed at achieving personal balance in the five fitness domains of physical, emotional, social, family, and spiritual well-being (U.S. Army 2013). This concept of resilience leverages the psychological history at the individual level, as well as the organizational history of resilience applying it to unit readiness. While this more recent focus on personal resilience is different from urban and infrastructure resilience, it does provide cultural context and insight into a resilient system process that is aimed at social resilience. The stated vision is an established community comprised of resilient individuals who are adaptive leaders of character and who develop cohesive teams capable of accomplishing a range of missions in environments of uncertainty and persistent danger (U.S. Army 2013). These principles of adaptation in the face of risk 
and retained capability during uncertainty apply broadly to resilience beyond the individual level and inform an understanding of resilience in the military engineering and disaster planning contexts.

As mentioned in Chapter 1, the military considers resilience as a critical element in its ability to defend the homeland and protect vital national interests. DoDD 4715.21 applies broadly to the military departments, defense agencies, and defense operations worldwide, and it is intended to help safeguard the U.S. economy, infrastructure, environment, and natural resources (DoD 2016). It also aims to provide for the continuity of DoD operations, services, and programs. This directive provides an overt linkage of climate change strategy to resilience planning within a national security context and establishes federal policy related to security.

DoDD 4715.21 also directed defense agencies and military services to implement the 2014 DoD Climate Change Adaptation Roadmap (DoD 2014). The foreword of the roadmap document reaches back to the classic military strategist Carl von Clausewitz, who wrote in his 1832 book On War, that "all action must, to a certain extent, be planned in a mere twilight." His words recognize the level of uncertainty that planners have always confronted, and that they must apply the same maxim to planning for resilience in order to provide for climate change adaptation. Despite the action- and decision-oriented culture of the military, overt statements of uncertainty are important in applying risk management strategies that prioritize limited resources, with security agencies valuing consistent definition and quantification of uncertainty when possible. The desire to quantify risk around specified and desired functionalities as part of resilience will integrate the military understanding of resilience with the historical evolution of the term, as closely aligned in the engineering field. However, the policy and guidance needed to plan for regional and community resilience is more aligned with urban and regional planning concepts that could benefit by adopting a more ecology-based view of resilience that recognizes the dynamic and complex nature of systems and communities.

DoDD 4715.01 also established a useful definition for resilience at the policy and planning level. Resilience is "the ability to anticipate, prepare for, and adapt to changing conditions and withstand, respond to, and recover rapidly from disruptions" (DoD 2016). Historically, agencies within the DoD claim they have always considered resilience. For example, the U.S. 
Army Corps of Engineers' (USACE) Resilience Roadmap states that its engineers have incorporated resilient strategies for more than 200 years of the Corp's existence (USACE 2016). The enduring function and continued existence of some of the Corp's civil works and military engineering projects does testify to their incorporation of resilience. But does a single lock and dam facility that survives a flood event also ensure the resilience of the regional and national economy reliant upon that navigation system, the local and regional communities impacted by the flood, and the riverine ecosystem? Recognizing that different aspects of resilience depend on how three key questions for resilience are answered-namely, "to what", "of what", and "for whom." As a result, USACE is now looking at resilience on three different levels. Those three levels include (1) project (or facility), (2) system (or program), and (3) community (or regional) resilience. While project and system resilience are addressed extensively in public policy and design documents, the concepts of community resilience and the related broader urban ecology dynamics are still lacking. Details of the system approach currently used by the military and many security agencies to implement resilience concepts follows.

\subsection{Systems approach to resilience}

Resilient systems planning includes climate change, but is broader in overall scope. A resilient system is one that is robust enough to withstand severe blows, is adaptive and responsive to threats, and can mitigate the consequences of threats through response and recovery operations (Mandler 2013). Resiliency is not a single outcome, but rather a cradle-to-grave process for engineering, building, and operating a fault-tolerant, safe, secure, smart, efficient, and sustainable infrastructure system (Allen and Albert 2014). These descriptions of a resilient system focus on the built infrastructure and natural infrastructure and how they interact with the human and natural environments. The military is in the early stages of trying to align its current efforts in resilience and sustainability to help optimize resources and to avoid duplication or contradiction of efforts.

An exploration of how the military has integrated and distinguished resilience and sustainability is worthwhile because the two concepts are interrelated. The United States currently considers infrastructure resilience as a critical component of national security and so, it is integrated with sustainability goals. Often, the focus of resilience policies is to lay out a functional resilience target and then, attempt to provide a holistic checklist of considerations for a comprehensive approach to reaching the target. The 
approach considers systems dynamics and links to other systems, with the end product being an action plan. Resilience also becomes a way of achieving some of the sustainability goals established in many areas of government over the past 20 years. Using a deliberative planning approach, the military planner rationally identifies relevant planning factors and sets desired objectives of functionality or system equilibrium as related to resilience. A rational construct of ends-ways-means is then used to identify potential courses of action and to quantify risks associated with these courses of action to achieve objectives, and an acceptable action plan is then developed, approved, and implemented (or put on the shelf until needed).

As an example from the National Infrastructure Protection Plan (NIPP), the vision statement related to the transportation sector is "a secure and resilient transportation system, enabling legitimate travelers and goods to move without significant disruption of commerce, undue fear of harm, or loss of civil liberties" (U.S. DHS 2010). This vision captures the close relationship between security and resilience, as well as their interdependent relationships to the economy and social values. Similar to veins in the body that carry blood and oxygen to cells, a network of transportation systems and multiple modes of transportation provide resilience by ensuring the transportation infrastructure is robust enough to withstand severe blows by ensuring the infrastructure has adaptive responses and recovery operations (Mandler 2013). Both the infrastructure system's breadth and depth provide attributes of resilience; thus, planning and designing infrastructure with current and future climate and threat impacts evaluated will provide infrastructure system resiliency (Allen and Alberts 2014). To ensure a comprehensive consideration of resilience is undertaken and a consequential action is associated with each identified risk, federal agencies utilize planning factors related to resilience and develop associated risk response strategies.

\subsubsection{Planning factors}

Planning factors associated with resilience help identify how resilient a specific system or facility is, and what risk response strategy is warranted or viable. There are four resilience elements proposed by the Volpe National Transportations System Center's infrastructure resiliency framework: (1) fault tolerance, (2) adaptive solutions, (3) critical asset 
redundancy, and (4) mitigation (Barami 2013). Each element has associated management strategies and layered defense elements to improve the system's resilience.

\subsubsection{Fault-tolerant infrastructure}

Fault-tolerant infrastructure systems have design-based components that ensure adequate functional capacity and structural hardiness. The system is built with protective measures that enable it to resist severe blows, absorb shocks, withstand extreme events with tolerable levels of loss, and degrade gracefully if needed (Barami 2013). An example of fault tolerance is the construction of bridges that use seismic design criteria in earthquakeprone regions or that withstand vessel impacts if they cross navigable water.

\subsubsection{Adaptive solutions}

Adaptive solutions as part of a system are capable of anticipating and preventing risks, limiting hazards, and ensuring continuity of operations through access to smart decision-making capabilities and situational awareness. Adaptive solutions enhance system resiliency by providing agility and flexibility for taking alternative paths and making real-time decisions to avert looming threats or mitigate developing dangers (Allen and Alberts 2014).

An example of adaptive solutions is the National Oceanic and Atmospheric Administration's (NOAA) Search and Rescue Satellite Aided Tracking (SARSAT) system which serves as an automated adaptive decision-support tool that calculates precise location of mariners or vessels in distress, computes the probability of success for alternative approaches, and determines the most effective way to conduct search and rescue operations.

\subsubsection{Critical asset redundancy}

Critical asset redundancy contributes to system resiliency by providing redundant system components and spare safeguards. Critical asset redundancy provides operational flexibility and distributed functionalities that would enable system operators and users to substitute assets and modes of service or product delivery to avoid single-point failures. This flexibility enables the system to reorganize rapidly, shift inputs and resources, and sustain an acceptable level of functionality as the disruption unfolds 
(Barami 2013). An example of critical asset redundancy is the presence of both rail mass transit and bus rapid transit for people movement in urban areas. These same people-centric modes of transportation could be flexible enough to deliver supplies rather than people if needed for a pandemic scenario where quarantined areas would limit movement of personnel in order to contain an event's spread.

\subsubsection{Mitigation}

Mitigation as an element of infrastructure resilience is the ability to allay or ease the consequences of system failures through the system's response and recovery capabilities. Rapid response and recovery operations save lives, minimize the spread of hazards and their cascading effects, and reduce loss of valuable assets (Barami 2013). Decentralized system operations and local government or private entities that are capable first responders to natural or manmade disasters are an example of mitigation that contributes to system resilience.

\subsubsection{Risk response strategies}

Risk response strategies depend upon the risk tolerance identified for a specific infrastructure system. Risk response strategy options occur along a continuum that can include: avoid the risk (remove the opportunity for a risk event to occur), transfer the risk (transfer the consequences to something or someone else), mitigate the risk (take actions to lessen the impact or likelihood of occurrence), or accept the risk (accept the potential impacts as tolerable) (U.S. DOT 2012). Solutions can be incorporated into a long-term plan by using a risk management approach that identifies current and future threats to the system, assesses vulnerabilities and risk to the system, develops a strategy using risk-based prioritization, identifies opportunities for co-benefits and synergy across sectors, implements strategic options, and monitors and reevaluates implemented options.

While the military tends to isolate resilience analysis into separate functional areas that lend themselves to a more systems-based approach, the military is attempting to engage in planning for resilience at the community and regional levels. This engagement is evidenced by military representation in the "2011 Regional Disaster Resilience Guide," by The Infrastructure Security Partnership (TISP 2011), a partnership that includes military-related organizations such as the Society of American Military Engineers (SAME). The guide serves to identify focus areas, priorities, 
and actions that relate to community planning for resilience. The guide meets a very practical need for communities to start thinking about the critical systems within their communities and action plans to mitigate risk to those systems. The guide is directed more at short-term disasters that are symptoms of climate change, rather than the longer-term drift into more enduring disaster scenarios that require planned climate change adaptation strategies.

The current military aspects of community resilience planning encourage collaboration, but the military still has a more engineering- and systemsrelated approach. The military's focus is on development of concrete mitigation strategies and action plans rather than looking earnestly at the longer-term impacts of the broader urban ecosystems and at system-tosystem linkages that can result in cascading impacts and events. Missing from the current military discussion on using resilience as a means to prepare for climate adaptation is a robust inclusion of regional planning and urban ecology concepts that pull together the broad urban planning considerations of the natural environment, built environment, and social and health considerations into a unified ecological framework that has potential for a more comprehensive and inclusive planning approach. It is in this vein that community and regional resilience-part of the contemporary military planning dialogue related to climate change adaptation-can benefit from modern urban and regional resilience planning and the actively changing tools, techniques, and concepts of urban ecology. 


\section{Resilience in Urban Planning: Using Urban Socio-Ecology Concepts to Enhance Military Resilience Planning for Climate Change Adaptation}

With an understanding of resilience and its use in a military and security agency context presented in the previous sections, we now look at resilience and its role in urban planning and relation to climate change in order to glean prospects for a new lens through which the military can gain a refined vision. This review of resilience in urban planning will demonstrate that urban planning inherently uses a transdisciplinary concept of resilience, because the urban planner typically facilitates a blending of multiple domains and expertise from across fields that include ecology, sociology, psychology, engineering, and others. This transdisciplinary view informs the concept of resilience and integrates it with other modern concepts of sustainability, smart cities, and urban ecology along with associated tools and techniques for urban analysis that can benefit military resilience planning and are currently being used or under development by urban planners.

Urban is a broad term that connotes a contrast with rural landscapes that are characterized as wild or devoted to natural resource management with economies based on commodification of natural resources. The term urban includes cities, suburbs, and exurbs (Pickett et al. 2013). Although resilience planning is not limited in its scope to urban areas, because the majority of the population and key infrastructure are in urban areas and highly developed urban and regional planning processes are in place, an examination of urban planning and resilience offers opportunities for expanded military planning considerations that are related to resilience and climate adaptation.

The concept of urban resilience relates to the ecology definition and the capacity of a system to tolerate disturbance without collapsing into a qualitatively different state (Holling 1973). From an urban systems perspective, this resilience is often seen as an urban areas' ability to withstand shock, whether derived from human, nature, or environmental sources (Young et al. 2006). More recently, the term urban resilience has been used to de- 
scribe the capacity of an urban place to withstand the influence of a changing climate (Heller et al. 2015; Meerow et al. 2015; Shove 2010). This description suggests there are various approaches to planning for resilient places (Fiksel 2006; Godschalk 2003; Zimmerman 2001; Bell 2002; and Bulkeley and Betsill 2005, 2013). For example, Folke et al. (2002, 439) argues for a better "understanding the complex connections between people and nature". While Fiksel (2006) proposes analyzing multiple models simultaneously in order to simulate redundancy and iteration, both considered essential urban resilience characteristics. Others have described a range of dichotomies that need to be resolved when considering urban resilience: redundancy and efficiency, diversity and interdependence, strength and flexibility, autonomy and collaboration, and planning and adaptability (Godschalk 2003, Zimmerman 2001, Bell 2002). All of these approaches offer a useful lens to view the diverse climate change challenges of cities from climate refugees to food shortage to rising tides.

Social science suggests a need for an interdisciplinary approach to urban resilience with strong linkages to social theory (Gillard et al. 2016). Most of these theories also refer to the criticality of understanding the inextricable link between social and ecological systems (Collier et al. 2013; Gillard et al. 2016). Although there has been a plethora of studies on the independent systems that comprise urban environments-energy, water, vegetation, climate, and waste (Kennedy 2011; Kennedy, Pincetl, and Bunje 2011; Grimm et al. 2000; Pickett et al. 2008) - still little is known of these systems with respect to their role in ecosystem functioning and ecosystem services within urban environments (McPhearson et al. 2014). More specifically, there is a lack of the ecologically based research needed to scale up plot-based field experiments that address the data needs of planners, policy makers, and managers. Such research could facilitate a more robust science of resilient cities (McPhearson et al. 2016). The urban ecology concept is now serving as a bridge to integrate these systems in theory and practice, and this transdisciplinary approach benefits urban and military planning.

Debate still exists regarding the distinctions and interfaces of sustainability and resilience for urban planners, as previously mentioned for military planners, too. The concept of resilience offers a means to address the longterm evolution of the built environment and to explore implications of changing conditions on the efficacy of differing approaches in planning, design, operation, management, value, and governance (Hassler and 
Kohler 2014). Sustainability and climate change research provides a growing awareness of risk, and it has brought attention to fragilities and the need to create resilience across the spectrum of urban planning and design (Hassler and Kohler 2014). Related to infrastructure and specifically to transportation, one argument is made that sustainable transportation is the result of intentional policy at the strategic level, and it also potentiates unified governance and economic growth. Thus, sustainable transportation is critical in peacekeeping and stability operations (Allen and Albert 2014). Sustainable transportation for peace and stability can best be accomplished with a comprehensive approach, starting with a long-term vision that is focused on balancing the key sustainability principles of transportation resilience, economic development, environmental health, and social values (Allen and Albert 2014). If this premise is accepted, then resilience is a related component of sustainability that is elevated to joint importance with the traditional triad components related to social, economic, and environmental balance in decision making that characterizes current urban planning processes and impact considerations. Elevating resilience thus elevates climate adaptation and incorporates both with sustainability in urban planning.

The concept of smart cities, with a focus on big data and optimized processes that improve efficiency and the quality of life for a population, and its relation to resilience is another area of current opportunity and growth. In contrast to notions of socio-environmental resilience, smart cities often emphasize a user's "perception and experience in the environment" without a clear connection to ecological-based processes (Davoudi et al. 2012). Subsequently, although the smart city concept espouses improvements to the quality of life of (smart) citizens, it tends to undervalue the critical environmental systems needed to achieve these improvements. (Neirotti et al. 2014). Many smart cities are also beginning to reexamine the use of big data and smart principles to enhance security and improve citizen safety. The concepts of smart cities and utilization of big data have implications for urban resilience and opportunity to inform military planning in urban areas.

In terms of data, smart city projects typically make use of sensor networks to monitor real-world, real-time systems; provide real-time adjustments and alerts to possible anomalies; make use of distributed installations; and use various formats and interfaces for data dissemination (Neirotti et al. 2014). A weakness in the approach is the problem of big data. Enormous 
volumes of data are generated, only some of which are relevant, most of which describe static and stable conditions. As demonstrated previously, urban ecology assumes a more dynamic condition. The aim is to monitor both human and environmental systems that act as indicators to socio-environmental stress. Where smart city efforts tend to be directed toward optimizing a city's operational performance related to physical and economic infrastructure (Neirotti et al. 2014), socio-environmental urban resilience efforts are directed toward the ability of a city to withstand shock such as climate-driven refugee influx, pollutants, extreme weather events, and other environmentally related stresses that might influence the long-term health and viability of both human and natural systems (McPherson 2016). Smart cities currently emphasize data collection from the internet of things, utilities, and publicly monitored devices like traffic cameras, physical infrastructure sensors, or traffic counts. Socio-environment resilience requires adding data that relates to water quality, climate, species richness, and habitat and vegetative diversity (for example) as important indicators of urban health, vitality, and the potential resilience of a place.

Collecting disparate data from varied sources with wide-ranging reliability to perform data analytics that inform decisions in a relevant manner is a core capability of military intelligence and security agencies. Thus adapting planning approaches in the military culture for intelligence assets to perform this broader analysis in existing and notional urban space is a key opportunity for collaboration of military and urban planners and for leveraging smart technology.

The importance of leveraging smart city technology and big data to improve security is now at the fore of planning for safety and security of urban populations in Europe. The argument that government's basic role is the protection via the provision of security for its citizens certainly affects the quality-of-life objectives of smart cities. Hazard and disaster management systems can leverage real-time data on weather or other natural disasters, criminal or terrorist activities, and traffic congestion or related incidents that either directly or indirectly relate to resilience and climate adaptation strategies. The American Association of State Highway and Transportation Officials (AASHTO) has identified three dimensions or facets of resilience as follows: (1) emergency management, (2) design engineering, and (3) climate, community, and societal changes (AASHTO 2017). Each of these facets can leverage data sets specific to that dimension, such as travel times for emergency management, bridge structural 
condition for design engineering, and carbon emissions for climate, community, and societal changes.

Resilience principles in urban planning continue to expand the planning process, tools, and techniques utilized. It requires a greater awareness of broader contexts and potential implications that enable decisions that are more readily adaptable to changing circumstance (Deal and Chakraborty 2010). Folke et al. (2005) submit that the path toward community resilience is built on a form of dynamic governance that involves all citizens. They advocate for empowering and equipping all members of a community with an ability to participate equally in the planning process. This equal participation necessitates planning tools that can facilitate two-way communication between expert system (the information) and user (stakeholder, decision maker, or citizen planner).

However, the connectedness of data and exchange of knowledge and information implies a polycentricism to resilience planning that extends beyond the user experience (Young et al. 2006). The resilience perspective emphasizes the connection between social and environmental systems and thus, the need to incorporate environmental systems and monitoring into smart city and planning support systems development. Adding and understanding socio-ecological relationships to smart approaches however, will require the dynamic collection of additional environmental and social data along with dynamic modeling approaches that can evaluate and interpret the collected data. Further, the integration of data from these various "big" sources, formatting and functional interoperability in itself, presents significant challenges (Buccella, Cechich, and Fillottrani 2009) and to date, models have not frequently been used to illustrate impacts of adaptation on urban functionality (Collier et al. 2013).

The computational basis for urban big data has thus far emphasized urban data acquisition techniques, data structures and communication protocols, real-time analysis, and some short-term projection capabilities. This focus ignores the connection to longer time-frame analysis, environmental data and impact analysis, and visualization techniques that are critical to planning for resilient places. According to Collier et al. (2013), an information infrastructure is needed to secure and understand the aspects of diverse meta-datasets-origin, content, purpose, format and access-which inform models that simulate environmental function. This can be accomplished 
through the use of planning support technologies and systems. The military can benefit from adopting these emerging technologies in their community and regional resilience analysis process as it relates to climate change adaptation; therefore a brief description of some of these tools and techniques follows.

Contemporary urban planning resilience concepts call for the use of technology to help communities visualize change in spatial phenomena and to help facilitate more rapid response to environmental stresses using dynamic insight regarding land development (Collier et al. 2013, Folke et al. 2005). The use of models provide insight and the means to visualize options and trade-offs between different urban scenarios which may consider development, environmental stressors, the addition or subtraction of job centers, and other important variables. Collier et al. (2013) note that current land-use models however, tend to focus on the process of urbanization and its relation to urban form and few have been used to illustrate the effects of adaptation in urban areas. To plan for adaptation and resilience, the linkage between land-use models, and assessment of urban function must be improved. Likewise the limitations of existing data streams that do not account for the plethora of environmental data that are needed must be acknowledged (Collier et al. 2013). For military planners, these items can fall into the category of 'known unknowns' in analyzing urban areas that inform the risk management process.

Current discussions regarding planning support technology literature acknowledge the need to shift from prescriptive-based approaches to: the management of information needs (Power and Sharda 2009), use-based systems (Deal and Pallathucheril 2008), and web-based strategies of information retrieval and delivery (Budthimedhee et al. 2002; Deal and Pallathucheril 2009a), in an effort to determine how "information and communications technologies might improve the functioning of cities" (Batty et al. 2012, 483). Planners have been employing these technologies to understand a range of urban phenomena including, land use change over time, transportation networks, the metabolic flux of cities, etc. Some of these tools and models can provide planners with the means to understand, analyze, and predict macro-scale attributes that go beyond a reductionist view of explicit characterizations of subsystem components. Some scholars argue that planning support system models can provide quantifiable and replicable information, help manage uncertainty, provide feedbacks, and help understand lags in complex urban system dynamics (Deal 
and Pallathucheril 2009b). These tools have been shown to help planners understand the socio-ecological impact of planning decisions and the complex hierarchical dependencies that often foster unanticipated or emergent behavior under external stress such as climate change or dwindling resources. This type of tool offers key insights for military and security agency planners who strive to understand how government intervention that may be slight or severe can have unintended second, third, or fourth order effects. These tools can help understand the complex urban ecosystems in a more comprehensive way.

Smart concepts may add to resilience and security, but may pose new security and resilience concerns. Adoption of these enhanced systems are not without challenges. Security and legal issues arise with the use of many smart technologies related to cyber security, personal privacy, data storage, and data ownership. Going back to the three basic questions of resilience 'to what', 'of what', and 'for whom' complicate the risk of leveraging smart technologies.

Concern over defensive urbanism that protects select classes and demographics while disenfranchising others must be considered by urban and military planners alike. Security demands and technology developments will continue the growth of smart and resilient innovations in urban areas, however, a transdisciplinary approach that includes elements of social justice and equity must balance gains in resilience to ensure the 'for whom' is inclusive of the broader society and not just a select minority.

Combining military and urban planning efforts for resilience offers great benefit in integrating the concepts discussed in this and previous sections. Both are evolving and both have knowledge gaps. Current urban system models, are driven by socio-economic and socio-physical factors, but missing are the links to socio-environmental elements that the emerging concept of urban ecology seeks to bridge (Pickett et al. 2013). Thinking about the future of urban resilience and how both urban and military planners can benefit from improved analysis tools for climate adaptation will guide research and investment in planning tools and techniques moving forward. In order to tackle the complexity of urban systems and resilience, the next generation of planning support systems and tools should be an interactive decision-making environment that collects data to gain an evolving self-awareness about its context, manipulates this data, and presents 
information to users in a useful and timely manner. A form of system intelligence would support urban and military planners as they attempt to resolve conflicts among different interests and assess risk in proposed courses of action or inaction. The challenges of large volumes of data and complex model support to make urban resilience based policy decisions that adequately includes critical ecological, environmental, and social data is best faced by combining the expertise of those proficient in both urban and regional planning and military planning professionals. 


\section{Summary and Conclusions: Improved Military Climate Resilience Planning with Contemporary Urban Systems Thinking}

This paper demonstrated the interconnection of military resilience planning with climate change adaptation. The paper began with an overview of the historical context of the term resilience in relation to varied fields of study, and then followed with an examination of planning for resilience in both the military planning paradigm and the contemporary urban planning context, as related to climate change. The discussion concluded that military resilience planning can benefit by understanding and adopting some of the theory, tools, and techniques offered by the contemporary blending of ecology and urban design with planning to result in modern urban ecology and socio-environmental planning concepts.

The discussion introduced military approaches to developing action plans and their foundation in national strategy documents, policies, and guidance. The review of military resilience included the three layers of resilience concepts (project, system, and community levels) built into military regulations and policies for implementing resilience strategies for achieving climate change adaptation. The argument then examined urban ecology concepts that proffer an ecologically based, socio-environmental perspective of resilience planning. Such a perspective can benefit the military planning process as it seeks to fully understand cascading impacts of planning intervention, as related to climate adaptation strategies. Common challenges face both urban and military planners. Those challenges include the following: (a) appropriately integrating resilience with sustainability, (b) understanding issues related to "smart" approaches, (c) developing tools and processes for analysis of urban ecologies to inform planning in current and future environments, and (d) working across interdisciplinary fields. Urban planning and military planning can work collaboratively so that system linkages related to ecological/environmental health, social values, and resilience can be incorporated into the overall security planning lexicon.

Achieving urban resilience requires a transdisciplinary approach that appeals to a broad range of expertise in order to plan for resilience that adequately considers emerging patterns, trends, and threats. Future 
challenges include the need for continuous monitoring of physical, economic, social, ecological, and environmental systems. This monitoring allows the study of current and (potentially resilient) future states, improves the ability to adapt to potential state changes, and develops methods for governing these systems in inclusive ways. Like urban ecosystems, planning information must be dynamic and forward-looking, and it must have relatively long time horizons. By pursuing intentional transdisciplinary planning efforts, military and urban planners can collaborate to help frame and refine the dynamic concept of resilience and to integrate the many facets of resilience into their climate change adaptation strategies in a more unified and enlightened manner. 


\section{References}

AASHTO. 2017. Understanding Transportation Resilience: A 20116-2018 Roadmap for Security, Emergency Management, and Infrastructure Protection in Transportation Resilience. National Cooperative Highway Research Program, Project 20-59-14C. Washington, DC: American Association of State Highway and Transportation Officials.

Adger, W.N. 2000. "Social and Ecological Resilience: Are they related?" Progress in Human Geography 24(3): 347-364.

Allen, James P., and Blace C. Albert. 2014. Sustainable Transportation: Strategy for Security, Prosperity, and Peace. Carlisle, PA: United States Army War College Press. http://www.dtic.mil/get-tr-doc/pdf?AD=ADA612253.

Barami, Bahar. 2013. "Infrastructure Resiliency: A Risk-Based Framework.” Paper prepared for Beyond Bouncing Back: A Roundtable on Critical Transportation Infrastructure Resilience held at the Volpe Center on April 30, 2013. Cambridge, MA: Center for Transportation and Logistics Security, The John A. Volpe National Transportation Systems Center, U.S. Department of Transportation.

Batty, M. K. W. Axhausen, F. Giannotti, A. Pozdnoukhov, A. Bazzani, M. Wachowicz, G. Ouzounis, and Y. Portugali. 2012. "Smart Cities of the Future." The European Physical Journal Special Topics 214(1):481-518.

Bell, Michael A. 2002. The Five Principles of Organizational Resilience. Report of Gartner Research, ID Go0103658. Stamford, CT: Gartner, Inc. https://www.gartner.com/doc/351410/principles-organizational-resilience.

Buccella, Agustina, Alejandra Cechich, and Pablo Fillottrani. 2009 "Ontology-Driven Geographic Information Integration: A Survey of Current Approaches." Computers \& Geosciences 35(4): 710-23. doi:10.1016/j.cageo.2008.02.033.

Budthimedhee, Kanjanee, Jinghuan Li, and R. Varkki George. 2002. "ePlanning: A Snapshot of the Literature on Using the World Wide Web in Urban Planning." Journal of Planning Literature 17(2): 227-246. https://doi.org/10.1177/088541202762475964.

Bulkeley, Harriet and Michelle Merrill Betsill. 2005. Cities and Climate Change: Urban Sustainability and Global Environmental Governance, Vol. 4. Hove, UK: Psychology Press. . 2013. "Revisiting the Urban Politics of Climate Change." Environmental Politics 22(1):136-154.

Carter, Jeremy G., Gina Cavan, Angela Connelly, Simon Guy, John Handley, and Aaleksandra Kazmierczak. 2015. "Climate Change and the City: Building Capacity for Urban Adaptation.” Progress in Planning 95 (January 2015): 1-66. doi:10.1016/j.progress.2013.08.001. 
Collier, Marcus J., Zorica Nedović-Budić, Jeroen Aerts, Stuart Connop, Dermot Foley, Karen Foley, Darryl Newport, Siobhan McQuaid, Aleksander Slaev, and Peter Verburg. 2013. "Transitioning to Resilience and Sustainability in Urban Communities." Cities 32 (Supplement 1): S21-28. doi:10.1016/j.cities.2013.03.010.

Davoudi, Simin, Keith Shaw, L. Jamila Haider, Allyson E. Quinlan, Garry D. Peterson, Cathy Wilkinson, Hartmut Fünfgeld, Darryn McEvoy, Libby Porter, and Simin Davoudi. 2012. "Resilience: A Bridging Concept or a Dead End? 'Reframing' Resilience: Challenges for Planning Theory and Practice Interacting Traps: Resilience Assessment of a Pasture Management System in Northern Afghanistan Urban Resilience: What Does It Mean in Planning Practice? Resilience as a Useful Concept for Climate Change Adaptation? The Politics of Resilience for Planning: A Cautionary Note." Planning Theory \& Practice 13(2): 299-333. doi:10.1080/14649357.2012.677124.

Deal, Brian M., and A Chakraborty. 2010. "Cyber-physical Planning Support Systems: Advancing Participatory Decision Making in Complex Urban Environments." International Journal of Operations and Quantitative Management 16(4): 353367.

Deal, Brian, and Daniel Schunk. 2004. "Spatial Dynamic Modeling and Urban Land Use Transformation: A Simulation Approach to Assessing the Costs of Urban Sprawl." The Journal of Ecological Economics 51(1-2): 79-95.

Deal, Brian M., and Varkki Pallathucheril. 2007. "Developing and Using Scenarios.” In Engaging the Future: Forecasts, Scenarios, Plans, and Projects, 221-42.

. 2008. "Simulating Regional Futures: The Land-Use Evolution and Impact Assessment Model (LEAM)." in Planning Support Systems for Cities and Regions, edited by R. Brail. Cambridge, MA: Lincoln Institute for Land Policy.

" "A Use-Driven Approach to Large-Scale Urban Modeling and Planning Support.” 2009a. In Planning Support Systems: Best Practice and New Methods, edited by Stan Geertman and John Stillwell, 29-51. New York, NY: Springer.

. 2009b. "Sustainability and Urban Dynamics: Assessing Future Impacts on Ecosystem Services.” Sustainability 1: 346-362. doi:10.3390/su1030346.

Deal, Brian, Varkki Pallathucheril, Yong Wook Kim, and Haozhi Pan. 2015. "Sentient PSS for Smart Cities." In Planning Support Systems and Smart Cities, edited by Stan Geertman, Joseph Ferreira, Robert Goodspeed, and John Stillwell, 281-96. Switzerland: Springer International Publishing Switzerland. https://link.springer.com/chapter/10.1007/978-3-319-18368-8_15.

DoD. 2014. Climate Change Adaptation Roadmap. (June). Washington, DC: U.S. Department of Defense, Office of the Assistant Secretary of Defense for Energy, Installations, and Environment, Environment, Safety, and Occupational Health Directorate.

DoD. 2016. Climate Change Adaptation and Resilience. DoDD 4715.21, 14 January. Washington, DC: U.S. Department of Defense, Office of the Under Secretary of Defense for Acquisition, Technology, and Logistics. 
DoD. 2018. DOD Dictionary of Military and Associated Terms. Washington, DC: U.S. Department of Defense.

Dorer, Viktor, Jona Allegrini, Kristina Orehounig, Peter Moonen, Govinda Upadhyay, Jerome Kämpf, and Jan Carmeliet. 2013. "Modelling the Urban Microclimate and Its Impact on the Energy Demand of Buildings and Building Clusters." In: Proceedings of BS2013: 13th Conference of International Building Performance Simulation Association, Chambéry, France, August 26-28, 3483-3489.

Everly Jr., George S. 2011. "Building a Resilient Organizational Culture.” Harvard Business Review (June 24). https://hbr.org/2011/06/building-a-resilient-organizat.

Fiksel, Joseph. 2006. "Sustainability and Resilience: Toward a Systems Approach." Sustainability: Science, Practice, \& Policy 2(2): 14-21.

Fletcher, David, and Mustafa Sukar. 2013. "Psychological Resilience: A Review and Critique of Definitions, Concepts, and Theory." European Psychologist 18(1): 1223 .

Folke, Carl, Steve Carpenter, Thomas Elmqvist, Lance Gunderson, C.S. Holling, and Brian Walker. 2002. "Resilience and Sustainable Development: Building Adaptive Capacity in a World of Transformations." AMBIO: A Journal of the Human Environment 31(5): 437-440.

Folke, Carl, Thomas Hahn, Per Olsson, and Jon Norberg. 2005. "Adaptive Governance of Social-Ecological Systems.” Annual Review of Environment and Resources 30: 441-73.

Gattis, Vanessa M. 2017. A Case Study of Work Place Bullying, Resilience, and Professional Women. Doctoral dissertation. Phoenix, AZ: Grand Canyon University, Proquest Dissertations Publishing Company no. 10267434.

Gillard, Ross, Andrew Gouldson, Jouni Paavola, and James Van Alstine. 2016. "Transformational Responses to Climate Change: Beyond a Systems Perspective of Social Change in Mitigation and Adaptation: Transformational Responses to Climate Change." Wiley Interdisciplinary Reviews: Climate Change 7(2): 25165. doi:10.1002/wcc.384.

Godschalk, David R. 2003. "Urban Hazard Mitigation: Creating Resilient Cities.” Natural Hazards Review 4(3): 146-143.

Graber, Rebecca, Florence Pichon, and Elizabeth Carabine. 2015. "Psychological Resilience: State of Knowledge and Research Agendas." Overseas Development Institute Working Paper 425. London, JK: ODI Climate and Development Programme. https://www.odi.org/publications/9596-psychological-resilience-stateknowledge-future-research-agendas.

Grimm, Nancy B., J. Morgan Grove, Steward T.A. Pickett, and Charles L. Redman. 2000. "Integrated Approaches to Long-Term Studies of Urban Ecological Systems." BioScience 50(7): 571-584.https://doi.org/10.1641/00063568(2000)050[0571:IATLTO]2.0.C0;2.

Hassler, U., and N. Kohler. 2014. "Resilience in the Built Environment." Building Research and Information 42(2): 119-129. doi: 10.1080/09613218.2014.873593. 
Heller, Nicole E., Jason Kreitler, David D. Ackerly, Stuart B. Weiss, Amanda Recinos, Ryan Branciforte, Lorraine E. Flint, Alan L. Flint, and Elisabeth Micheli. 2015. "Targeting Climate Diversity in Conservation Planning to Build Resilience to Climate Change." Ecosphere 6(4): 1-20. doi:10.1890/ES14-00313.1.

Holling, C.S. 1973. "Resilience and Stability of Ecological Systems." Annual Review of Ecology and Systematics, vol. 4: 1-23. https://doi.org/10.1146/annurev.es.04.110173.000245.

IPCC. 2014. "Summary for Policymakers." In Climate Change 2014: Impacts, Adaptation, and Vulnerability. Part A: Global and Sectoral Aspects. Contribution of Working Group II to the Fifth Assessment Report of the Intergovernmental Panel on Climate Change [C.B. Field, C.B.,V.R. Barros, D.J. Dokken, K.J. Mach, M.D. Mastrandrea, T.E. Bilir, M. Chatterjee, K.L. Ebi, Y.O. Estrada, R.C. Genova, B. Girma, E.S. Kissel, A.N. Levy, S. MacCracken, P.R. Mastrandrea, and L.L. White (eds.)]. Cambridge (U.K.) and New York, NY: Cambridge University Press.

Kennedy, C., S. Pincetl, and P. Bunje. 2011. "The Study of Urban Metabolism and Its Applications to Urban Planning and Design.” Environmental Pollution 159(8-9): 1965-1973. doi:10.1016/j.envpol.2010.10.022

Mandler, M. 2013. "Volpe Speaker Series Examines Ways to Enhance Transportation System Resilience.” Event Announcement. Cambridge, MA: The John A. Volpe National Transportation Systems Center, U.S. Department of Transportation.

Masten, A.S., K.M. Best, N. Garmezy. 1990. "Resilience and Development: Contributions from the Study of Children who Overcome Adversity." Development and Psychopathology 2(4): 425-424.

McPhearson, Timon, Zoé A. Hamstead, and Peleg Kremer. 2014. "Urban Ecosystem Services for Resilience Planning and Management in New York City." AMBIO 43(4): 502-15. doi: 10.1007/s13280-014-0509-8.

Meerow, Sara, Joshua P. Newell, and Melissa Stults. 2016. "Defining Urban Resilience: A Review." Landscape and Urban Planning 147(March 2016): 38-49. doi:10.1016/j.landurbplan.2015.11.011.

Neirotti, Paolo, Alberto De Marco, Anna Corinna Cagliano, Giulio Mangano, and Francesco Scorrano. 2014. "Current Trends in Smart City Initiatives: Some Stylised Facts.” Cities 38 (June 2014): 25-36. doi:10.1016/j.cities.2013.12.010.

Norberg, Jon, and Graeme Cumming, ed. 2008. Complexity Theory for a Sustainable Future. New York, NY: Columbia University Press.

Pallathucheril, Varkki, and Brian Deal. 2012. "Communicative Action and the Challenge of Discounting." Presented at the 53rd Annual Conference of the Association of Collegiate Schools of Planning, Cincinnati, Ohio.

Pickett, Steward T.A., Mary L. Cadenasso, J. Morgan Grove, Peter M. Groffman, Lawrence E. Band, Christopher G. Boone, William R. Burch (and more). 2008. "Beyond Urban Legends: An Emerging Framework of Urban Ecology, as Illustrated by the Baltimore Ecosystem Study.” BioScience 58(2): 139-150. https://doi.org/10.1641/B580208. 
Pickett, Steward T.A., Mary L. Cadenasso, and Brian McGrath, ed. 2013. Resilience in Ecology and Urban Design: Linking Theory and Practice for Sustainable Cities. Future City 3, doi 10.1007/978-94-007-5341-9_1. Dordrecht, Netherlands: Springer Science+Business Media.

Power, Daniel J., and Ramesh Sharda. 2009. “Decision Support Systems,” In Springer Handbook of Automation, edited by Shimon Y. Nof. Heidelberg, Germany: Springer.

Shove, Elizabeth. 2010. "Beyond the ABC: Climate Change Policy and Theories of Social Change." Environment and Planning A 42(6): 1273-1285. https://doi.org/10.1068/a42282.

Stewart, I. D., and T. R. Oke. 2012. "Local Climate Zones for Urban Temperature Studies." Bulletin of the American Meteorological Society 93(12):1879-1900. https://doi.org/10.1175/BAMS-D-11-00019.1.

TISP. 2011. “2011 Regional Disaster Resilience Guide.” In Regional Disaster Resilience: A Guide for Developing an Action Plan. Arlington, VA: The Infrastructure Security Partnership.

UN. 2014. World Urbanization Prospects: The 2014 Revision. ST/ESA/SER.A/366. New York, NY: United Nations, Department of Economic and Social Affairs, Population Division.

USACE. 2016. U.S. Army Corps of Engineers Resilience Initiative Roadmap. Washington, DC: Headquarters, U.S. Army Corps of Engineers.

U.S. Army. 2013. The United States Army's Ready and Resilient Campaign. https://www.army.mil/readyandresilient/. Washington, DC: Headquarters, Department of the Army.

U.S. DHS. 2010. 2010 Transportation Systems Sector-Specific Plan, An Annex to the National Infrastructure Protection Plan. Washington, DC: Department of Homeland Security.

U.S. DOT. 2012. Risk-Based Asset Management: Examining Risk-Based Approaches to Transportation Asset Management, Report 2. Washington, DC: U.S. Department of Transportation, Office of Asset Management, Federal Highway Administration.

U.S. Office of the President. 2013. Presidential Policy Directive 21: Critical Infrastructure Security and Resilience (PPD-21). Washington, DC: The White House.

Wu, Jianguo and Tong Wu. 2013. "Ecological Resilience as a Foundation for Urban Design and Sustainability." In Resilience in Urban Ecology and Design: Linking Theory and Practice for Sustainable Cities, 211-230, edited by Steward T.A. Pickett, Mary L. Cadenasso, Brian P. McGrath, and Kristina Hill. Springer.

Young, Oran R., Frans Berkhout, Gilberto C. Gallopin, Marco A. Janssen, Elinor Ostrom, and Sander van der Leeuw. 2006. "The Globalization of Socio-Ecological Systems: An Agenda for Scientific Research.” Global Environmental Change 16(3): 304-16. doi:10.1016/j.gloenvcha.2006.03.004. 
Zimmerman, R. 2001. "Social Implications of Infrastructure Network Interactions." Journal of Urban Technology 8(3): 97-119. 


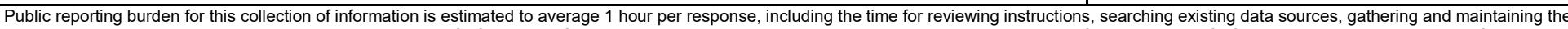

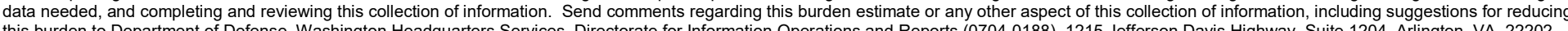

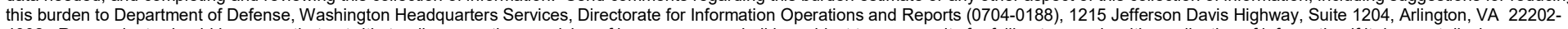

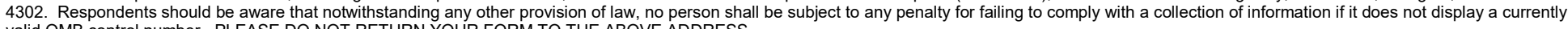
valid OMB control number. PLEASE DO NOT RETURN YOUR FORM TO THE ABOVE ADDRESS.

\section{REPORT DATE (DD-MM-YYYY) \\ December 2017 \\ 4. TITLE AND SUBTITLE \\ 2. REPORT TYPE \\ Final Report \\ Military Climate Resilience Planning and Contemporary Urban Systems Thinking}

3. DATES COVERED (From - To)

5a. CONTRACT NUMBER

5b. GRANT NUMBER

5c. PROGRAM ELEMENT NUMBER

T45

5d. PROJECT NUMBER

455009

5e. TASK NUMBER

5f. WORK UNIT NUMBER

\section{PERFORMING ORGANIZATION NAME(S) AND ADDRESS(ES)}

U.S. Army Engineer Research and Development Center (ERDC)

Construction Engineering Research Laboratory (CERL)

PO Box 9005

Champaign, IL 61826-9005
8. PERFORMING ORGANIZATION REPORT NUMBER
ERDC/CERL MP-17-4

\section{SPONSORING / MONITORING AGENCY NAME(S) AND ADDRESS(ES)}

Assistant Secretary of the Army for

Acquisition, Logistics, and Technology (ASA(ALT))

103 Army Pentagon

Washington, DC 20314-1000

10. SPONSOR/MONITOR'S ACRONYM(S)

ASA(ALT)

11. SPONSOR/MONITOR'S REPORT NUMBER(S)

12. DISTRIBUTION / AVAILABILITY STATEMENT

Approved for public release. Distribution is unlimited.

\section{SUPPLEMENTARY NOTES}

\section{ABSTRACT}

Climate change adaptation is now recognized through many formal government policies as a desired strategic end state, with resilience as the identified means to achieve it. Military and security agencies clearly see that climate change adds significantly to instability, hunger, poverty, and conflict. Thus the military requires planning consideration for risk environments. The evolving military concept of resilience can leverage sustainability and smart concepts with added emphasis on security and planned risk response strategies.

The work reported here establishes the nexus of climate change adaptation with military resilience planning, reviews the military's use and definition of resilience as a concept, and explores what the military might learn from urban planning and nonmilitary versions of resilience. It also examines planners' focus on engineering resilience at the project level and at the system level. A gap in planning for resilience at the community (or regional) levels is recognized in the current military planning paradigm, and this work examines how planners can fill this gap and benefit by expanding the current resilience framework. This broadened and more comprehensive consideration of resilience will enhance climate change adaptation strategies of the military, and resilience should be incorporated into overall military planning.

\section{SUBJECT TERMS}

Climatic changes--Risk management, Military planning, City planning, Resilience

\section{SECURITY CLASSIFICATION OF:}

a. REPORT Unclassified b. ABSTRACT Unclassified

17. LIMITATION
OF ABSTRACT
UU

\begin{tabular}{c|c} 
18. NUMBER \\
OF PAGES
\end{tabular}

